Document downloaded from:

http://hdl.handle.net/10251/44821

This paper must be cited as:

Canós-Darós, L. (2013). An algorithm to identify the most motivated employees. Management Decision. 51(4):813-823. doi:10.1108/00251741311326581.

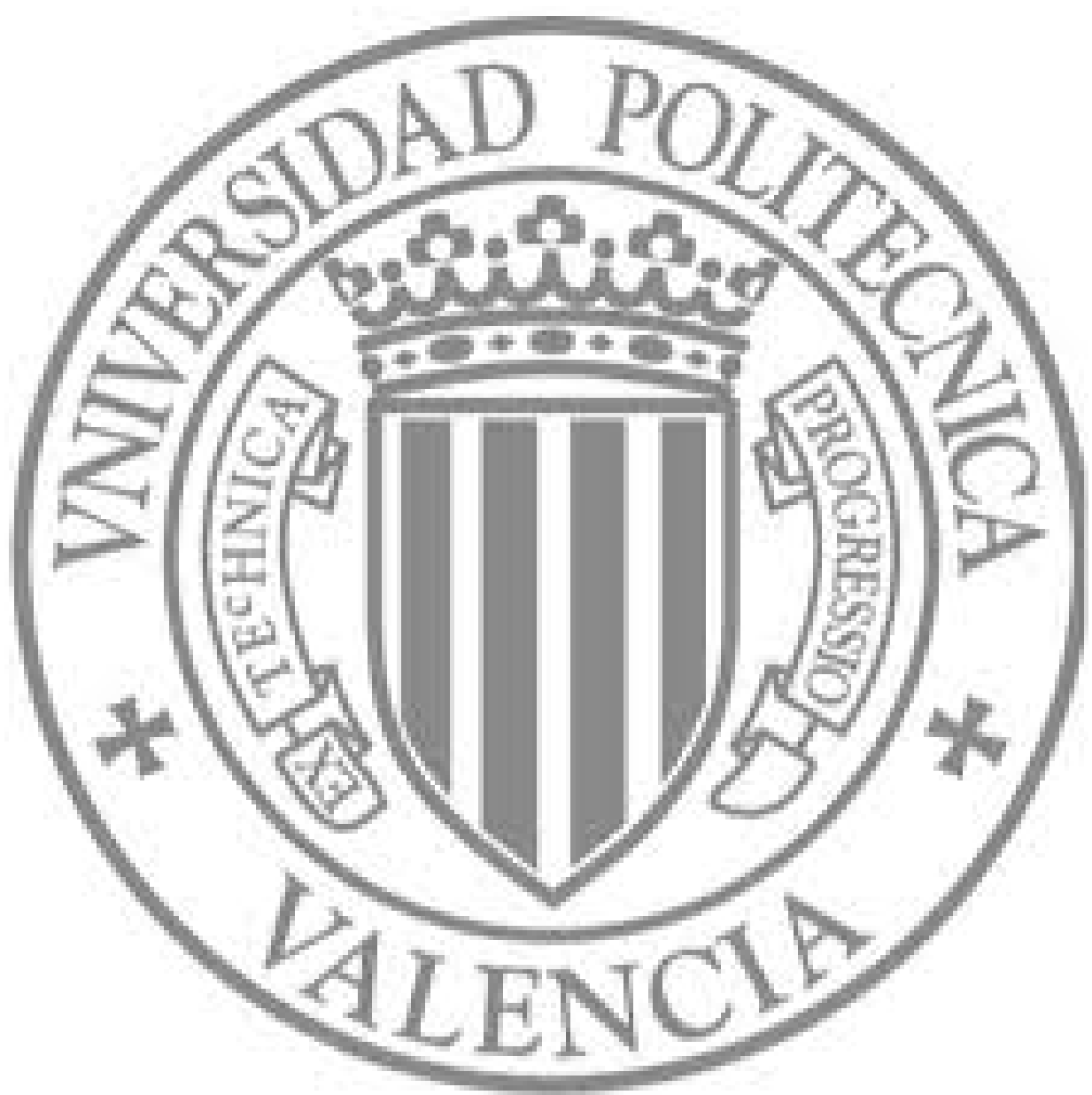

The final publication is available at

http://dx.doi.org/10.1108/00251741311326581

Copyright Emerald 


\section{An algorithm to identify the most motivated employees}

\section{Introduction}

Employees in knowledge-based companies have to be very motivated in order to achieve corporate social and economic objectives. In any industry, motivation has been usually considered as a determining factor of performance, productivity and quality of work. This feature is a key point for the survival of a firm in innovative and knowledge industries, whose main strategic asset is human resources management (highly educated knowledge employees are responsible for performing complex, multidimensional, and interdependent tasks). Knowledge workers commonly follow good practices as to share their knowledge with teammates or to be proactive, flexible and adaptable (Badoo et al., 2006).

In such circumstances, managers might take the wrong decisions if they do not use appropriate resources or if they do not have a clear strategy and objectives for innovation and knowledge management (Gholipur et al., 2011). Managers might think that all the motivation factors have the same influence on all the employees; that people are motivated primarily by money or awards; or even that those same employees do not need any motivation at all until a problem appears (Peterson, 2007). Indeed, employees assimilate complex combinations of motivation factors and consider not only reward incentives but also other professional aspects (Glen, 2006).

We define motivation as the willingness to exert and maintain an effort towards a particular set of behaviors and towards organizational goals to be processed serially (Dieleman, 2006; Tabassi and Bakar, 2009). Then, motivation is a complex and multidimensional phenomenon indexed in terms of selection of pursuits from competing alternatives, intensity of effort and persistence of exertion (Vollmeyer and Rheinberg, 2000). In the same way, an incentive is one particular form of payment in order to achieve some specific change in behavior (Mathauer and Imhoff, 2006).

Motivation policies and practices are carried on to encourage the desired behaviors of individuals, teams or organizational behavior (Campbell et al., 1996; Peterson, 2007; Reis and Peña, 2001; van Knippenberg, 2000). Traditional motivation theories are Vroom's expectancy theory, Adams' equity theory, Herzberg's two-factor theory, Mc Gregor's Theory X and Theory Y, McClelland achievement, affiliation and power motivation or Myers-Briggs type indicator, among others. The application of these theories has been very effective when it comes to analyzing and changing behaviors (Tietjen and Myers, 1998). Behavior depends on multiple factors, but managers can try to control it by using mechanisms as positive reinforcement, negative reinforcement, punishment and extinction. In this context, employees who are not highly motivated do not have any control on their work results because they are concerned about reaching their work goals (Orpen, 1994). To avoid these situations, it is necessary to know the motivation factors and their importance for managers and employees. However, 
due to the subjectivity underlying motivation processes, managers and employees can have different beliefs, expectations and points of view about the same reality. DeVoe and Iyengar (2004) present a study developed in a multinational firm that shows differences in managers' and employees' perceptions about motivation factors in North America, Asia and Latin America. Although employees reported themselves to be more motivated by intrinsic than by extrinsic incentives, North American managers thought their employees were more extrinsically than intrinsically motivated; Asian managers perceived subordinates as equally motivated by intrinsic than by extrinsic factors; and Latin American managers reckoned their employees were more intrinsically than extrinsically motivated.

In this context, managers face the challenge to measure the influence of different factors on their employees. This may be a problem because extra tension and stress is introduced in the daily performance, thus reducing satisfaction. Moreover, measures can be deficient, include personal bias, deliberate distortion and other errors (Campbell et al., 1996). However, measures are useful for human-resources decision making because the use of indicators reduces subjectivity and interdependency. Even if managers are dealing with intrinsic or extrinsic motivation, different factors can be measured. There are different scales for this, for example, behaviorally anchored rating scales (BARS), behavioral observation scales (BOS), behavioral discrimination scales (BDS), and Cassidy and Lynn achievement motivation scale (CLAMS) (Campbell et al., 1996; Story et al., 2009).

It would be useful for managers to include subjective information in the formal decision making process, because the mathematical model can be affected by the numerical accuracy of the introduced quantities. An appropriate approach in this context is the fuzzy set theory (Zadeh, 1965). Fuzzy theory considers both uncertainty in data and the capacity to add any subjective information. Besides, it is closer to human thinking than traditional mathematics.

In the next section, we develop some reflections about an exhaustive list of motivation factors found in literature. Then, we present an algorithm to compare the perception that employees have on the use of motivation factors in the company with the ideal created by managers, by using an adequacy index. Finally, we show some conclusions and a list of references.

\section{Motivation factors}

We cannot find a consensus in literature about the exact number of motivating factors and how to conceptualize this construct in the best way (Story et al., 2009). As an example, some papers focused in different motivation factors are listed in Table 1.

Insert Table 1 
It is well known that human-resources management practices as supervision, recognition, performance management, training, promotion, leadership, participation, communication, planning, acquisition of employees, retention, decision making or positive environment creation, may affect motivation (Mathauer and Imhoff, 2006; Peterson, 2007; Tabassi and Bakar, 2009). Therefore, we can consider these practices as a first source of motivation factors.

The importance of reward policy in motivation is remarkable. An example of how particular compensation practices affect work performance and affective commitment of workers with higher education can be read in Kuvaas (2006). Nevertheless, sometimes the use of extrinsic incentives could lead to a lessening of the effort in generating profits (James Jr., 2005).

Other motivation factors different from reward are also important in an innovative and knowledge-based industry. For example, managers can use recognition, bring opportunities for achievement, job security, good leadership, supportive management and design a technically challenging work (Badoo et al., 2006; Mathauer and Imhoff, 2006). In some particular industries and locations, non-financial incentives are more effective than financial ones, such as health workers in Mali, motivated by responsibility, training and recognition, next to salary (Dieleman et al., 2006) or such as health workers in Benin and Kenya, strongly guided by their professional conscience, recognition, career development and further qualification (Mathauer and Imhoff, 2006).

In addition, self-motivation is almost always present in knowledge workers. Autonomous motivation refers to types of motivation that involve internal processes through which people come to identify with and internalize the value of an activity (Story et al., 2009).

\section{Identification of motivated employees}

Our goal is to identify the most motivated employees, that is, the employees identified with corporate motivation policies designed by managers.

In the model presented in this paper, we use fuzzy numbers to order employees' perceptions about motivation factors in the company according to managers' ideal. Different fuzzy ordering techniques can be found in Yager (1981), Chen (1985), Yuan (1991), Choobineh and Li (1993), Fortemps and Roubens (1996), Wang and Kerre (2001a; 2001b).

Let us consider a group of $n$ employees where we want to identify the most motivated ones. Let us call $E=\left\{e_{1}, \ldots, e_{n}\right\}$ the set of employees. 
First, we choose the motivation factors to be considered by both employees and managers, i.e., $M=\left\{m_{l}, \ldots, m_{R}\right\}$. In our model, motivation factors are classified into 8 types and $R=78$ as we can see in Table 2.

Insert Table 2

Second, each employee evaluates motivation factors according to his or her perception. Because of general characteristics of people in knowledge-based industries, we suppose that the perception of the implementation of different motivation factors in the company is enough to establish a representative profile of the motivation of each employee.

For this, employees assign a number between 0 and 1 that reflects his or her perception of the importance of a particular motivation factor, i.e., we have the following matrix:

$$
\begin{array}{ccccc} 
& m_{1} & m_{2} & \cdots & m_{R} \\
\tilde{e}_{1} & b_{m 1}^{1} & b_{m 2}^{1} & \cdots & b_{m R}^{1} \\
\tilde{e}_{2} & b_{m 1}^{2} & b_{m 2}^{2} & \cdots & b_{m R}^{2} \\
\vdots & \vdots & \vdots & \ddots & \vdots \\
\tilde{\boldsymbol{e}}_{n} & b_{m 1}^{n} & b_{m 2}^{n} & \cdots & b_{m R}^{n}
\end{array}
$$

Motivation factors evaluation done by each employee can be seen as the fuzzy set (type 1)

$\tilde{e}_{j}=\left\{\left(m_{i}, \mu_{m_{i}}\left(\tilde{e}_{j}\right)=b_{m_{i}}^{j} \in[0,1]\right)\right\}_{i=1}^{R}$

for all $j=1, \ldots, n$.

However, sometimes it is difficult to assign an exact numerical value because of human idiosyncrasy. In this case, we can permit possible values by using a subinterval of $[0,1]$.

$$
\begin{array}{ccccc} 
& m_{1} & m_{2} & \cdots & m_{R} \\
\tilde{e}_{1}{ }^{\Phi} & {\left[b_{m 1}^{11}, b_{m 1}^{21}\right]} & {\left[b_{m 2}^{11}, b_{m 2}^{21}\right]} & \ldots & {\left[b_{m R}^{11}, b_{m R}^{21}\right]} \\
\tilde{e}_{2}{ }^{\Phi} & {\left[b_{m 1}^{12}, b_{m 1}^{22}\right]} & {\left[b_{m 2}^{12}, b_{m 2}^{22}\right]} & \ldots & {\left[b_{m R}^{12}, b_{m R}^{22}\right]} \\
\vdots & \vdots & \vdots & \ddots & \vdots \\
\tilde{e}_{n}{ }^{\Phi} & {\left[b_{m 1}^{1 n}, b_{m 1}^{2 n}\right]} & {\left[b_{m 2}^{1 n}, b_{m 2}^{2 n}\right]} & \ldots & {\left[b_{m R}^{1 n}, b_{m R}^{2 n}\right]}
\end{array}
$$

Therefore, each employee's evaluation can be seen as the $\Phi$-fuzzy set (type 2)

$$
\tilde{e}_{j}^{\Phi}=\left\{\left(m_{i}, \mu_{m_{i}}\left(\tilde{e}_{j}^{\Phi}\right)=\left[b_{m_{i}}^{1 j}, b_{m_{i}}^{2 j}\right] \in e([0,1])\right)\right\}_{i=1}^{R} \text { for all } j=1, \ldots, n .
$$


Third, managers design the profile of ideal motivation factors:

$\tilde{I}=\left\{\left(e_{i}, \mu_{e_{i}}(\tilde{I})=a_{e_{i}} \in[0,1]\right)\right\}_{i=1}^{R}$

or a $\Phi$-fuzzy set as

$$
\tilde{I}^{\Phi}=\left\{\left(e_{i}, \mu_{e_{i}}\left(\tilde{I}^{\Phi}\right)=\left[a_{e_{i}}^{1}, a_{e_{i}}^{2}\right] \in P([0,1])\right)\right\}_{i=1}^{R}
$$

Obviously, organization culture and strategy are considered by managers to create the ideal. Ideal can be constructed by one manager (for instance, a human resources manager), by a group of managers (we can calculate an average or we can use other means) or by an expert or a group of experts if the company needs external assessment.

Finally, we analyze the fitting of each motivation factor profile provided by employees to ideal profile. For this, we can use the adequacy index. When we deal with type-1 fuzzy sets, the adequacy index is calculated as

$$
\begin{aligned}
& K_{m i}\left(e_{j} \rightarrow I\right)=\min \left\{1,1-a_{m i}+b_{m i}^{j}\right\} \\
& K\left(e_{j} \rightarrow I\right)=\frac{1}{R} \sum_{i=1}^{R} K_{m i}\left(e_{j} \rightarrow I\right)
\end{aligned}
$$

If we are dealing with $\Phi$-fuzzy sets, we could calculate the $\Phi$-adequacy index defuzzifying ex ante by applying the above mentioned method or ex post by calculating

$$
\begin{aligned}
& K_{m i}^{\phi}\left(e_{j} \rightarrow I^{\phi}\right)=\frac{l\left(\left[b_{m_{i}}^{1 j}, b_{m_{i}}^{2 j}\right] \cap\left[a_{m_{i}}^{1}, a_{m_{i}}^{2}\right]\right)}{l\left(\left[b_{m_{i}}^{1 j}, b_{m_{i}}^{2 j}\right] \cup\left[a_{m_{i}}^{1}, a_{m_{i}}^{2}\right]\right)} \\
& K^{\phi}\left(e_{j} \rightarrow I^{\phi}\right)=\frac{1}{R} \sum_{i=1}^{R} K_{m i}\left(e_{j} \rightarrow I^{\phi}\right)
\end{aligned}
$$

Adequacy indexes (one per employee) are ranked from highest to lowest, so that the motivation factors profile given by an employee with the highest coefficient is the most similar to the one provided by managers. 


\section{Conclusions}

Motivation is a key human-resources policy in innovative and knowledge-based companies. In these kinds of industries, employees are usually very motivated because of their own idiosyncrasy, but how much are they motivated? Can we construct a ranking? The answer to these questions is interesting for managers in order to personalize leadership practices, training or promotion, due to the fact that motivation can be the reason (one criterion) to design human-resources actions. In this paper, we present an algorithm to identify the most motivated employees according to corporate motivation policies designed by managers.

Measuring human-resources features is not easy. Nonetheless, the translation of pure qualitative information to figures is useful in human resources decision making. Mathematical models offer quick and clear solutions. On the other hand, managers do not often understand (and they do not have to) complicated reasoning, but they can support decision making with mathematical results. In addition, subjectivity and uncertainty from human perceptions should be added to the formal decision-making process. With this aim, we use an adequacy index tool based in fuzzy set theory.

Furthermore, we intend to construct more tools related to the management of motivation policies. For instance, it would be interesting to know the most motivating factors for a team in order to promote them not only individually, but also as a group. As it is well known, teamwork is a common thing to knowledge-based companies.

\section{References}

Badoo, N.; Hall, T. and Jagielska, D. (2006), "Software developer motivation in a high maturity company: a case study”, Software process improvement and practice, Vol. 11, pp. 219-228.

Campbell, D.J.; Campbell, K.M. and Chia, H.-B. (1996), "Merit pay, performance appraisal, and individual motivation: an analysis and alternative", Human Resources Management, Vol. 37, No. 2, pp. 131-146.

Chen, S.H. (1985), "Ranking fuzzy numbers with maximizing set and minimizing set”, Fuzzy Sets and Systems, Vol. 17, pp. 113-129.

Choobineh, F. and Li, H. (1993), “An index for ordering fuzzy numbers”, Fuzzy Sets and Systems, Vol. 54, pp. 287-294.

Cory, S.N.; Ward, S. and Schultz, S.A. (2007), "Managing human resources in a small firm. Motivation through performance evaluation", The CPA Journal, October, pp. 62-65.

DeVoe, S.E. and Iyengar, S.S. (2004), "Managers' theories of subordinates: a cross-cultural examination of manager perceptions of motivation and appraisal of performance", Organizational Behavior and Human Decision Processes, Vol. 93, pp. 47-61. 
Dieleman, M.; Toonen, H.; Touré, H. and Martineau, T. (2006), “The match between motivation and performance management of health sector workers in Mali”, Human resources for health, Vol. 4, pp. $2-9$.

Fortemps, P. and Roubens, M. (1996), "Ranking and defuzzification methods based on area compensation", Fuzzy Sets and Systems, Vol. 82, pp. 319-330.

Garg, P. and Rastogi, R. (2006), "New model of job design: motivating employees performance", Journal of Management Development, Vol. 25, No. 6, pp. 572-587.

Gholipour, A.; Pirannejad, A.; Kozekanan, S.F. and Gholipour, F. (2011), "Designing motivation system to produce creativity and entrepreneurship in petrochemical company", International Journal of Business Management, Vol. 6, No. 5, pp. 137-144.

Glen, C. (2006), "Key skills retention and motivation: the war for talent still rages and retention is the high ground", Industrial and Commercial Training, Vol. 38, No. 1, pp. 37-45.

Gordon, J. (2010), "Why your company needs motivation more than ever and six ways you can share it", The Receivables Report, December, pp. 7-9.

James Jr., H.S. (2005), "Why did you do that? An economic examination of the effect of extrinsic compensation on intrinsic motivation and performance", Journal of Economic Psychology, Vol. 26, pp. 549-566.

Kuvaas, B. (2006), "Work performance, affective commitment, and work motivation: the roles of pay administration and pay level", Journal of Organizational Behaviour, Vol. 27, pp. 365-385.

Mathauer, I. and Imhoff, I. (2006), "Health worker motivation in Africa: the role of non-financial incentives and human resources management tools", Human resources for health, Vol. 4, pp. 24-41.

Orpen, C. (1994), "Interactive effects of work motivation and personal control on employee job performance and satisfaction”, The Journal of Social Psychology, Vol. 134, No. 6, pp. 855-856.

Peterson, T.M. (2007), "Motivation: How to increase project team performance", Project Management Journal, Vol. 38, No. 4, pp. 60-69.

Reis, D. and Peña, L. (2001),"Reengineering the motivation to work", Management Decision, Vol. 39

No. 8, pp. 666-675.

Story, P.A.; Hart, J.W.; Stasson, M.F. and Mahoney, J.M. (2009), "Using a two-factor theory of achievement motivation to examine performance-based outcomes and self-regulatory processes", Personality and Individual Differences, Vol. 46, pp. 391-395.

Tabassi, A.A. and Bakar, A.H.-A. (2009), “Training, motivation, and performance: The case of human resource management in construction projects in Mashhad, Iran", International Journal of Project Management, Vol. 27, pp. 471-480.

Tietjen, M.A. and Myers, R.M. (1998),"Motivation and job satisfaction", Management Decision, Vol. 36, No. 4, pp. 226-231.

Van Knippenberg, D. (2000), "Work motivation and performance: a social identity perspective", Applied Psychology: an International Review, Vol. 49, No. 3, pp. 357-371. 
Vollmeyer, R. and Rheinberg, F. (2000), "Does motivation affect performance via persistence?" Learning and Instruction, Vol. 10, pp. 293-309.

Wang, X. and Kerre, E.E. (2001a), "Reasonable properties for the ordering of fuzzy quantities (I)", Fuzzy Sets and Systems, Vol. 118, pp. 375-385.

Wang, X. and Kerre, E.E. (2001b), "Reasonable properties for the ordering of fuzzy quantities (II)", Fuzzy Sets and Systems, Vol. 118, pp. 387-405.

Yager, R.R. (1981), “A procedure for ordering fuzzy subsets of the unit interval”, Information Sciences, Vol. 24, pp. 143-161.

Yuan, Y. (1991), “Criteria for evaluating fuzzy ranking methods”, Fuzzy Sets and Systems, Vol. 44, pp. 139-157.

Zadeh, L.A. (1965), “Fuzzy Sets”, Information and control, Vol. 8, pp. 338-353. 
Table 1. Motivation factors in literature.

\begin{tabular}{|c|c|}
\hline Authors & Motivation factors \\
\hline Badoo et al. (2006) & $\begin{array}{l}\text { Proactivity, flexibility, adaptability, share knowledge, good practice, } \\
\text { pay and benefits, recognition, achievement, social or political } \\
\text { environment. }\end{array}$ \\
\hline Cory et al. (2007) & $\begin{array}{l}\text { Ongoing understanding of performance ability, individual development } \\
\text { plan, training, strategic thinking, initiative, influence, conceptual } \\
\text { thinking, change orientation, developing self and others, teamwork, } \\
\text { relationship building, communication, results orientation, technical } \\
\text { excellence. }\end{array}$ \\
\hline DeVoe and Iyengar (2004) & $\begin{array}{l}\text { Need for self-actualization, monetary incentives, managerial } \\
\text { surveillance. }\end{array}$ \\
\hline Garg and Rastogi (2006) & $\begin{array}{l}\text { Feedback from others, dealing with others, meaningfulness of work, } \\
\text { responsibility for work, knowledge of results, general satisfaction, pay } \\
\text { satisfaction, security satisfaction, social satisfaction, supervisory } \\
\text { satisfaction, use of technologies, ergonomics, organizational culture, } \\
\text { leadership style, human performance improvement. }\end{array}$ \\
\hline Glen (2006) & $\begin{array}{l}\text { Organizational process, role challenge, values, work-life balance, } \\
\text { information, reward, recognition, management, work environment. }\end{array}$ \\
\hline Gordon (2010) & Fear, negativity, faith, beliefs, optimism, caring of managers. \\
\hline Kuvaas (2006) & Variable pay, fixed pay. \\
\hline Mathauer and Imhoff (2006) & $\begin{array}{l}\text { Professional conscience, recognition, career development, continuous } \\
\text { education, good leadership, supportive management, wage increases, } \\
\text { allowances, performance-related bonuses, housing, basic salary, health } \\
\text { insurance premium, granting unpaid holidays, token awards, } \\
\text { recreational facilities, recognition, supervision, encouragement, } \\
\text { responsibility, training, relationship with colleagues, job description. }\end{array}$ \\
\hline Peterson (2007) & $\begin{array}{l}\text { Friendly work atmosphere, team unity, team success, team agreement, } \\
\text { internal or external communication, risk, competition, appreciation, } \\
\text { personal acknowledgment, empowerment. }\end{array}$ \\
\hline Story et al. (2009) & $\begin{array}{l}\text { Work ethic, acquisitiveness for money and material wealth, dominance } \\
\text { pursuit of excellence, competitiveness, status, mastery. }\end{array}$ \\
\hline Tabassi and Bakar (2009) & Knowledge, expertise, money, recognition, team belonging. \\
\hline van Knippenberg (2000) & $\begin{array}{l}\text { Membership vs. personal identity, conflict, competition, organizational } \\
\text { commitment, dispositional group loyalty, appreciate and admire the } \\
\text { employee, promotion, salary, wages, bonuses, cash prizes, coupons, } \\
\text { respect, dignity, position. }\end{array}$ \\
\hline Vollmeyer and Rheinberg (2000) & Mastery confidence, incompetence fear, challenge, interest. \\
\hline
\end{tabular}


Table 2. Motivation factors for knowledge-based companies.

\section{SELF MOTIVATION}

1. Proactivity / Initiative

2. Flexibility / Adaptability

3. Recognition

4. Achievement

5. Relationship building

6. Relationship with colleagues

7. Friendly work atmosphere

8. Need for self-actualization
9. Responsibility for work

10. Optimism

11. Risk

12. Competitiveness

13. Dominance pursuit of excellence

14. Expertise

15. Incompetence fear

16. Interest

\section{MANAGEMENT}

1. Supportive management

10. Influence

2. Organizational process

11. Encouragement

3. Ongoing understanding of results

12. Personal acknowledgment

4. Training / Continuous education

13. Managerial surveillance

5. Strategic thinking

14. Supervisory satisfaction

6. Conceptual thinking

15. Mastery confidence

7. Change orientation

16. Appreciate and admire the employee

8. Results orientation

17. Caring of managers

9. Leadership style

18. Empowerment

\section{DEVELOPMENT}

1. Career development / Promotion

4. General satisfaction

2. Individual development plan

5. Social satisfaction

3. Developing self and others

6. Organizational commitment

\section{JOB DESIGN}

1. Ergonomics

4. Job description

2. Work environment

5. Role challenge

3. Meaningfulness of work

COMMUNICATION

1. Share knowledge

5. Use of technologies

2. Feedback from others

6. Technical excellence

3. Internal/external communication

7. Knowledge of results

4. Information

\section{MONETARY INCENTIVES}

1. Pay satisfaction

2. Pay and benefits / Reward

3. Variable pay and fixed pay
6. Performance-related bonuses

7. Cash prizes

8. Coupons 
4. Wage increases

9. Acquisitiveness

5. Allowances

\begin{tabular}{|c|c|c|}
\hline \multicolumn{3}{|l|}{ TEAM } \\
\hline & Team work & 4. Team agreement \\
\hline & Team unity & 5. Team belonging \\
\hline 3. & Team success & 6. Dispositional group loyalty \\
\hline \multicolumn{3}{|c|}{ ETHICS } \\
\hline & Organizational culture & 5. Values / Beliefs \\
\hline & Follow good practice & 6. Professional conscience \\
\hline & Work ethic & 7. Work-life balance \\
\hline & Faith & 8. Dignity \\
\hline \multicolumn{3}{|c|}{ OTHERS } \\
\hline & Social or political environment & 5. Granting unpaid holidays \\
\hline & Security satisfaction & 6. Recreational facilities \\
\hline 3. & Housing & 7. Awards \\
\hline 4. & Health insurance premium & 8. Status / Position \\
\hline
\end{tabular}

